\title{
Acceder a la gestión de lo simbólico. Un derecho ciudadano
}

Antoni Remesar

CR POLIS- Research gropu "CRIT". Universitat de Barcelona

Email: aremesar@ub.edu

Javier Vergel

CR POLIS- Research gropu "CRIT". Universitat de Barcelona

Email: jvergel@ub.edu

Recibido: 25 junio 2020

Evaluado: 30 julio 2020

Publicado: 5 septiembre2020 


\section{Resumen}

Significar el espacio urbano es una de las actividades más relevantes para permitir su conversión en espacio público, en convertir los sitios en lugares. Para ello es imprescindible ampliar el concepto de "accesibilidad" al nivel de la "accesibilidad simbólica" y entenderla como uno de los nuevos derechos urbanos.

El artículo desarrolla los conceptos de "simbolismo a priori" y "simbolismo a posteriori" como estrategias de intervención de significación del espacio público. El primero responde a las operaciones habituales desde la administración, el segundo a los procesos populares de apropiación del espacio.

Analizando la experiencia de participación creativa - hoy en curso- en el barrio barcelonés del Bon Pastor el artículo plantea la posibilidad de creación de un lugar de encuentro entre los dos tipos de simbolismo, mediante procesos de co-producción del espacio público, específicamente de su co-diseño.

Palabras clave: Espacio Público; Arte Público; Co-diseño; Participación ciudadana; Bon Pastor

\section{Summary}

\section{To access to manage the symbolic dimension. A citizen right}

To give meaning to urban space is one of the most relevant activities to allow its conversion into public space, in turning sites into places. For this, it is essential to expand the concept of "accessibility" to the level of "symbolic accessibility" and understand it as one of the new urban rights.

The article develops the concepts of "symbolism a priori" and "symbolism a posteriori" as intervention strategies of meaning of the public space. The first responds to the usual operations from the administration, the second to the popular processes of appropriation of space.

Analysing the experience of creative participation - today in progress - in the Barcelona neighbourhood of Bon Pastor, the article raises the possibility of creating a meeting place between the two types of symbolism, through processes of co-production of public space, specifically its co-design.

Key words: Public Space; Public art; Co-design; Citizen participation; Bon shepherd

\section{Resum}

\section{Accedir a la gestió del simbòlic. Un dret ciutadà}

Significar l'espai urbà és una de les activitats més rellevants per permetre la seva conversió en espai públic, en convertir els indrets en llocs. Per a això és imprescindible ampliar el concepte "d'accessibilitat"; al nivell de "I'accessibilitat simbòlica" i entendre-la com un dels nous drets urbans.

L'article desenvolupa els conceptes de "simbolisme a priori" i "simbolisme a posteriori" com a estratègies d'intervenció de significació de l'espai públic. El primer respon a les operacions habituals des de les administracions, el segon als processos populars d'apropiació de l'espai.

Analitzant l'experiència de participació creativa- avui en curs- al barri barceloní de Bon Pastor l'article planteja la possibilitat de creació d'un lloc de trobada entre els dos tipus de simbolisme, mitjançant processos de coproducció de l'espai públic, específicament del seu co-disseny.

Paraules clau: Espai Públic; Art Públic; Co-disseny; Participació ciutadana; Bon Pastor 


\section{Introducción}

La muerte de Georges Floyd en Minneapolis ha desencadenado una ola mundial de destrucción y agresión a monumentos erigidos a figuras que formarían parte del "patrimonio negativo", aquel asociado a la opresión, las dictaduras, la esclavitud o el colonialismo. Al mismo tiempo, esta oleada, ha evidenciado algo que, en situaciones de "normalidad", puede pasar desapercibido: la importancia que el arte público - en este caso el conmemorativo- adquiere en la configuración del imaginario simbólico de una sociedad. Por lo general, los monumentos quedan relegados a configurar el "fondo" del paisaje cotidiano y rara vez se revelan como "figura" poseyendo unos valores intrínsecos (paisajísticos, escultóricos...) y capacidad de trasmitir valores sociales que coadyuban a la construcción de la memoria social.

Por ello, es importante que la expresión de los valores sociales en el espacio público-mediante el monumento o la manifestación artística- se realice de manera cautelosa partiendo de consensos que permitan cumplir los objetivos de la conmemoración y del recuerdo: la transmisión de valores a las generaciones futuras. Pero la ola global iconoclasta, nos alerta, también, que la implantación de un monumento en el espacio público-el de todos- no debe responder únicamente a criterios de valor basados en la importancia que, para una ciudad, pudiera tener la figura a la que se rinde tributo, sino que, además, la vida de esta figura ha de ser coherente, en la totalidad de sus acciones, con los valores generales recogidos en la Declaración Universal de los Derechos Humanos o en la más reciente declaración de los Derechos Humanos Emergentes.

Esta visión prospectiva de la obra, se complementa con la visión retrospectiva, la que revisa aquello que nuestros antepasados nos legaron, "borrando" de las calles, plazas y parques, "símbolos" de un pasado en el que no nos reconocemos hoy, pero que, en definitiva, es el pasado y la memoria con la que debemos lidiar nuestros demonios individuales y colectivos, afectando, como se ha señalado recientemente por Noam Chomsky y otros intelectuales, al libre intercambio de información e ideas "the life blood of a liberal society, is daily becoming more constricted"(AA.VV 2020)

\section{Acceder a la gestión de lo simbólico: un derecho ciudadano}

La accesibilidad es uno de los modos de promover la inclusión y cohesión social. Puede operarse de una manera muy amplia y, tradicionalmente, se ha abordado desde dos orientaciones:

[A] la que hace referencia a la movilidad y transporte, relacionado con la cohesión territorial, que viene a caracterizar un enfoque propio de disciplinas como la geografía, la ingeniería de transporte o la planificación urbana y territorial (Sanz 1997; Pirie 1979; Bhat et al. 2000; Evans 2009); y

[B] la que está más relacionada con la usabilidad y funcionalidad que, a menudo, viene acompañada de reivindicaciones por parte de los colectivos con diversidad funcional. Este enfoque lo operan disciplinas de carácter proyectual como el urbanismo, el diseño urbano o la arquitectura (Iwarsson y Ståhl 2003; Wegge y Zimmermann 2007; Fernando 2007). 
No obstante, como se recuerda desde COCEMFE$^{1}$ o la Design for All Foundation, la accesibilidad universal no es únicamente un modo de incluir socialmente a las personas con diversidad funcional, sino que es un requisito indispensable para la inclusión del conjunto de diversidades, reconocidas o no, existentes en la sociedad, incluyendo 3a edad, mujeres, jóvenes, niños, minorías étnicas, etc.

El concepto de accesibilidad universal, cuando se proyecta en el espacio urbano, sitúa a la ciudadanía en una posición de mera usuaria-consumidora del entorno ya que la accesibilidad se tiende a evaluar respecto a variables mecanicistas como tiempo, coste de oportunidad, distancia, barreras, etc. En este sentido, el espacio urbano queda reducido a un dispositivo funcional que tiene que cumplir unas funciones concretas sujetas a unos requisitos y normativas pre-establecidas de accesibilidad.

Sin embargo, desde la concepción de triada dialéctica del espacio (Lefebvre 1978, E. Soja 1996; E. W. Soja 2008), el espacio urbano no es solo el espacio físico y formalmente objetivado,

"lo urbano, considerado como campo, no se concibe simplemente como un espacio vacío cubierto de objetos. (...) Es un campo de tensiones muy complejo; se trata de una virtualidad, un posible-imposible que busca lo realizado, una presencia-ausencia siempre renovada, siempre exigente" (Lefebvre, Henri 1971, 47-48)

El espacio urbano, tampoco es únicamente el espacio percibido e individualmente imaginado en términos de Lynch (1960), sino que es un espacio efectivamente vivido, y es aquel en el que se producen las interacciones sociales entre iguales y diferentes, entre conocidos y extraños; donde se desarrollan los consensos y los conflictos, donde se despliega la cotidianeidad, los procesos de reproducción social o la actividad política y contestataria.

Si se acude a la accesibilidad en términos de relación con la usabilidad y la funcionalidad, se está acudiendo a una concepción "moderna" del entorno urbano ya superada, a una concepción de ciudad como máquina (CIAM 1933), simplemente como "Urbs" despojándola de su componentes de "Polis" y "Civitas"( Borja y Muixi 2003, Capel 2003) o como plantea Sennet (2018) a una ciudad en la que predominan los valores de la "ville" sobre los valores de la "cité" (Sennett 2018).

No obstante, la accesibilidad (Ascher 2004) puede analizarse desde la garantía de acceso efectivo y universal, tanto a los bienes como a los servicios que se despliegan en la ciudad, adecuándose a una diversidad y complejidad social creciente.

Recuperando a Lefebvre (Lefebvre 1978) existen un conjunto de necesidades

que no satisfacen los equipos comerciales y culturales más o menos parsimoniosamente tenidos en consideración por los urbanistas. Nos referimos a la necesidad de actividad creadora, de obra (no sólo de productos y bienes materiales consumibles), de necesidades de información, simbolismo, imaginación, actividades lúdicas. (Lefebvre 1978, 163)".

Por ello, pensamos que sería necesario dar un paso adelante en cuanto a la definición de accesibilidad

1.- Confederación Española de Personas con Discapacidad Física y Orgánica 
y vincularla con el "derecho a la ciudad" y a los "derechos Humanos Emergentes"(IDHC 2009). Estos derechos están planteados desde los principios de "Inclusión social" y de "horizontalidad"². En el conjunto de derechos adaptados a una sociedad del siglo XXI., algunos de los artículos destacan para el propósito de introducir nuevas dimensiones al concepto. Así, el artículo 5, reconoce el derecho a la democracia pluralista, y en su parte 3 , el derecho al reconocimiento y protección de la identidad cultural común- El artículo 7 que reconoce el derecho a la democracia participativa se despliega en varios aspectos interesantes: Apartado 1. El derecho a la ciudad; Apartado 5. El derecho a la participación; Apartado 7. El derecho a los espacios públicos, monumentalidad y atractivo urbanístico; Apartado 9. El derecho a la conversión de la ciudad marginal en ciudad de ciudadanía.

En este contexto, podemos entender la accesibilidad urbana como un concepto operativo que viene a caracterizar la facilidad o dificultad que tiene la ciudadanía diversa en cuanto al ejercicio efectivo del "derecho a la ciudad". Busquet, resume en tres puntos lo que implica ejercer este derecho:

(1) el derecho a una renovada centralidad y apropiación de los símbolos y funciones ofrecidas por "la centralidad";

(2) el derecho a participar en las decisiones, a la autogestión de lo común y el derecho a la información; y

(3) el derecho a lo recreativo y supra funcional, es decir el derecho a desarrollar una cotidianeidad desalienada. (Busquet 2019, 3)

Esta visión supera el determinismo mecanicista antes señalado y aproxima una relación personaentorno, colectivos-entorno, fundamentada en la desalienación de la vida cotidiana, donde interviene la producción y el consumo, pero también la creación y la recreación, el descanso, la toma de decisiones, la protesta etc. En palabras de Harvey el derecho a la ciudad:

"es por tanto mucho más que un derecho de acceso individual o colectivo a los recursos que esta almacena o protege; es un derecho a cambiar y reinventar la ciudad de acuerdo con nuestros deseos". (Harvey 2013, 31:20)

Esta definición implica un ejercicio integrador. La accesibilidad, desde este punto de vista, tiene que garantizar la capacidad de la ciudadanía a desarrollar una vida creativa y facilitar la apropiación del espacio propiciando que los sitios devengan lugares. Para ello es fundamental vehicular participativamente, mecanismos que permitan a la ciudadanía dar forma y significar el espacio público (Rapoport 1982), sea desde la perspectiva del decoro urbano 3 (Remesar 2016), sea desde la

2.- Estas ideas subyacen también en la propuesta del llamado P2P Urbanism al reclamar el derecho fundamental a escoger el entorno construido en que vivimos, la implicación de la ciudadanía en los procesos de toma de decisiones y el derecho a participar en el co-diseño del entorno construido (Salingaros, Nikos A. 2010) o en las actuales aproximaciones a la co-producción en la gestión pública y la gobernanza urbana (Bovaird, T- Löffer, E (ed) 2016; Remesar, Antoni, 2020).

3.- Decoro urbano que transciende los aspectos formales -visuales, estéticos y simbólicos- y se expande hacia los nuevos modos de intervención sustentados en la idea de un Desarrollo Urbano Sostenible e Integral, armonizando 
perspectiva de plasmar la memoria cívica con el propósito de evitar la alienación que se manifiesta, como segregación [en relación al conjunto social de la ciudad], como dominación y cosificación cultural [en relación al medio institucional] y finalmente como extrañamiento [desorientación geográfica y extrañeza en relación al medio urbano] (Lefebvre, 1974: 45).

Cuando un grupo de la estructura social promueve la creación de un monumento, realiza un ejercicio de poder. Un poder que, cuando lo ejercitan los grupos que detentan el poder económico o político, se impone a la población - físicamente, la forma del monumento y simbólicamente, los contenidos y valores que transmite el monumento, así como sus valores estéticos-. Se imponen unas determinadas "representaciones del espacio". Mediante esta intervención se dota al espacio de forma, estructura y nombre que se pretenden compartidos y generales, pero que responden a los intereses de los grupos proponentes, al tiempo que se apartan o borran del espacio público, otros hechos, recuerdos y experiencias consideradas no deseables. Se crea un espacio simbólico con un significado prefijado que puede ser, o no, asimilado por la población y convertirse, o no, en un elemento simbólico compartido.(Pol, Enric 1997).

En cualquier caso, los grupos dominantes producen un tipo de intervención que podemos denominar "simbolismo a priori", al imponer al resto de la estructura social, formas, contenidos y valores. Las instancias con legitimidad y capacidad de intervenir sobre el espacio lo transforman mediante monumentos, el tratamiento formal, el nomenclátor y otros elementos de información y significado (Brandão 2011). Algunas veces, la intervención se adapta a los valores compartidos, la estética, la cultura y la tradición del conjunto de la población y, en este caso, el monumento se integrará fácilmente con los referentes compartidos y potenciará el refuerzo de la identidad colectiva. Pero otras muchas veces, la intervención no se adapta a las sensibilidades diversas de la población, rompiendo su curso de acción y tradición. Es entonces cuando se dan tres escenarios distintos: Rechazo, Indiferencia, Asimilación (Pol, Enric, 1997).

a) La población en general o grupos importantes de esta población, se sienten agredidos y rechazan activamente la intervención.

b) La población se siente ajena a la intervención y al valor simbólico dado. Por ello, la intervención no refuerza la identidad colectiva y la población la castiga con su indiferencia. El monumento abandona su papel de "figura" para integrarse en el decorado de calles, plazas o jardines (Vattimo, Gianni 1986) diluyéndose entre los elementos del decoro urbano, aunque ayudando a configurar el paisaje de la ciudad .

c) Aunque la intervención no se adecúa a la sensibilidad de la población, genera nuevos elementos, valores y símbolos (p. ej., modernidad, dinamismo, estatus, riqueza) que los grupos sociales evalúan positivamente. La intervención se asimila fácilmente como un referente identificador y un elemento colectivo como ha sucedido en algunas de las políticas de arte público desarrolladas desde la década de 1980.

los aspectos de intervención física, con los aspectos de sostenibilidad ambiental y social y de lucha contra la exclusión (Remesar, Antoni, 2016). 
En definitiva, una participación mecánica y escasa de los distintos grupos sociales producirán un producto-monumento alienado, frente al que la población responde, generalmente, con la ira destructora e iconoclasta, o con la indiferencia.

Frente a la relativa incapacidad de los grupos que detentan el poder efectivo, emergen prácticas sociales y espaciales que operan sobre objetos y lugares. Con el objetivo de proceder a su apropiación social, las poblaciones o grupos sociales intervienen sobre el espacio público mediante intervenciones de carácter artístico, como pueden ser los murales reivindicativos de colectividades marginadas; la instalación de esculturas "populares" en los espacios de un barrio; la creación de jardines en los barrios populares ${ }^{4} \mathrm{o}$ las intervenciones iniciales del denominado "Street art" antes de convertirse en un modo de expresión institucionalizado desde las instancias administrativas, económicas y artísticas.

Estas apropiaciones "cualifican al espacio colectivo y le otorgan su condición de espacio público". (Takano y Tokeshi 2007: 22). Estas son intervenciones simbólicas "a posteriori", es decir, apropiaciones, muchas veces sin contar con la administración local, de entornos que la colectividad valora como "degradados" o carentes de significado y que requieren la intervención para demostrar la voluntad de ejercitar las libertades urbanas y que una colectividad pueda considerarse igual a sus semejantes. El simbolismo "a posteriori" es fruto de la interacción social no mediada; las personas y los colectivos sociales cargan de significados a sus espacios de acción y relación que pasan a comportarse como lugares referenciales y vertebradores del colectivo. Estos espacios simbólicos "a posteriori" no tienen que tener una monumentalidad o unas especificidades formales concretas, ya que su devenir simbólico surge de la experiencia del grupo y no de su formalización explícita.

Sin embargo, este fenómeno también puede ocurrir en espacios preconcebidos con un significado "a priori", como sucedería con los llamados "espacios de memoria" (Nora 1989; Michonneau 2001) en los que mediante el uso repetitivo y ritual (prácticas espaciales) se produce una transcendencia del sitio vinculándolo con el sistema de representaciones sociales. En este caso, se requiere tiempo, un tiempo mayor o menor dependiendo de la situación. Por ello, los aspectos estructurales de la intervención, junto con las virtudes funcionales del espacio, son cruciales.

Estos dos caminos, "simbolismo a priori" y "simbolismo a posteriori", pueden converger o divergir en virtud de si lo que se busca expresar por parte de las instancias de poder es compartido o no por los diferentes colectivos sociales que viven en el territorio. (Valera y Pol 1994; Valera 1993).

Cuando para conformar, organizar y mantener un paisaje urbano capaz de generar una imagen de la ciudad compartida y asumida por la ciudadanía, la administración local debe establecer

4.- "Me ha sorprendido lo poco que se ha hecho por mejorar en este sentido los espacios públicos pobres. Cuando trabajaba con un presupuesto reducido en una zona pobre de Chicago, por ejemplo, mis clientes y yo empleábamos arbustos en macetas para lograr a lo largo de una calle el mismo efecto que los residentes del barrio de Medellín conseguían en sus balcones con la variación de las especies de arbustos, de manera que la pared continua tuviera el aspecto de una progresión. Los patrocinadores gubernamentales pensaron que era un adorno innecesario. Esas simples acciones implican algo más que el mero embellecimiento de la ciudad". (Sennett, Richard 2018, 309) 
políticas de "decoro urbano". Nos referimos a una "imagen de la ciudad" cotidiana, para todos, y no a la creación de una "imagen espectáculo" vinculada con el márquetin urbano que genera una "urbanalización" (Muñoz, Francesc 2008) de los paisajes. Estas políticas de decoro se sitúan en el plano de los sistemas urbanos (p.e. sistema de recogida de basuras; sistemas de señalización) y del diseño urbano, afectando a una gran cantidad de actuaciones, desde aquellas normativas (p.e. control de la publicidad, ocupación del espacio público por parte de actividades privadas) a las propiamente proyectuales (elección de los pavimentos, elementos de mobiliario urbano, y, obviamente, los proyectos o programas de arte público). Algunas de estas actuaciones serán comunes a toda la ciudad (extensivas) ejecutada por iteración (repetición) a lo largo y ancho de una ciudad (Remesar, A - Esparza, D 2014; Esparza, D 2017). Otras, más puntuales (intensivas), introduciendo nuevas formas y materiales, en zonas concretas de la ciudad. Estas actuaciones entrarían dentro de las operaciones de "simbolismo a priori".

Co-producir la significación del espacio público: punto de encuentro entre el "simbolismo a priori" y el "simbolismo a posteriori". Barrio del Bon Pastor (Barcelona)

Estas imágenes ilustran el contexto en el que iniciamos el proyecto "Hagamos la Memoria del Bon Pastor", un proyecto de co-diseño y participación creativa vecinal orientado a recuperar la memoria cívica, social e histórica del barrio ${ }^{6}$ Bon Pastor, un barrio de la periferia de Barcelona que desde 2001 se enfrenta a un profundo proceso de regeneración urbana. (Dictricte de Sant Andreu 2009; Angosto 2019; Salas 2016).

A través del proceso participativo que ha sustentado el proyecto y tras tres años de trabajo, varios talleres creativos, varios foros vecinales y un par de exposiciones, en diciembre de 2017 se concluyó con la redaccion de un "Plan Estratégico de Acción " que fue discutido entre los vecinos en el primer trimestre de 2018. Este Plan está construido sobre tres ejes temáticos principales de reivindicación de la memoria cívica y sobre los cuales se pretende desarrollar las intervenciones:

[1] Nuestro pasado y presente industrial,

[2] Aspectos urbanos de nuestro vecindario y

[3] Nuestros movimientos sociales y la lucha vecinal.

\footnotetext{
5.- Es demasiado habitual entender este concepto desde una lectura simplista de Lynch, especialmente de lo que el llamó "imágenes ambientales" (Lynch, Kevin 1960). Como señala el propio Lynch, la imagen de una ciudad no es el resultado exclusivo de la formación de imágenes ambientales. Como el propio Lynch estudiaría más adelante la "buena forma" de la ciudad se traduciría en "imágenes consistentes" dependiendo de cinco dimensiones de rendimiento espacial de las ciudades: Vitalidad, Sentido, Adecuación, Acceso y Control, a las que añade dos metacriterios: Eficacia y Justicia (Lynch, Kevin 1985)

6.- Con su origen en el "Mural de la Memoria" de Baró de Viver, 2011(Salas, Xavier 2015). Algún tiempo después de la inauguración del Mural de Baró, la Asociación de Vecinos de Bon Pastor nos propuso el desarrollo de un proyecto similar. Comenzamos a hablar en 2013, Asociación de Vecinos y Universidad, iniciando el proceso participativo en 2014. Más tarde, se firmó un acuerdo entre la Asociación de Vecinos, la Universidad y el Distrito de Sant Andreu (2016).
} 
Estas actuaciones son muy relevantes, puesto que Bon Pastor es uno de los pocos barrios de Barcelona que no ha obtenido beneficios de la política de Arte Público de la Ciudad. Por lo tanto, los vecinos entienden que el sistema espacial no es únicamente una operación de rescate de la memoria cívica sino un modo de introducir Arte Público en el barrio. Por ejemplo, entre las acciones planteadas se encuentran la propuesta de Monumento a las víctimas del bombardeo fascista de 1937; la rememoración del Centro Blanco, un antiguo edificio, ahora demolido, en la que se fundó la "Asociación de Cabezas de Familia", el embrión de la actual Asociación de Vecinos; la bienvenida en el río Besòs o el recuerdo de las luchas vecinales para conseguir el Metro.

Antes de las elecciones municipales de 2019, bajo la presión de los vecinos, el Distrito, aprovechando la remodelación de una de las plazas del barrio, "concedió", la construcción de uno de los puntos del sistema. Este punto es el dedicado a la "La Pinya", una antigua asociación cultural y recreativa que en los años 80 y principios de los 90 organizó las actividades que hoy se desarrollan el Centro Cívico y la Biblioteca del Bon Pastor.

Como se puede ver en la imagen, el punto de "La Pinya" no está completo. Falta el QR (o similares), necesario para conectar la parte física del sistema con la parte de Realidad Aumentada. Por el momento, se ha diseñado una maqueta del interfase web entre el "archivo" y el "sistema espacial" que actuaría como directorio de la información mostrada a través del sistema de realidad aumentada.

\section{La política meseográfica del MUHBA. Integrando periferias}

Desde hace unos años, el Museo de Historia de la Ciudad ha iniciado una política de "descentralización" de sus espacios expositivos, utilizando para ello, la conversión de viejos recintos industriales en desuso en equipamientos culturales. La idea central de esta política es equilibrar territorialmente los espacios museísticos de la ciudad, excesivamente concentrados en las áreas centrales (Ciutat Vella) y occidentales de la ciudad (políticas de accesibilidad territorial y cohesión urbana). Agua, industria y vivienda popular, son los ejes en los que se basan los nuevos espacios de exhibición de MUHBA en el territorio norte de Barcelona.

Con el objetivo de preservar una de las hileras de casas baratas, el MUHBA (Museo de Historia de Barcelona) inició un proyecto (2015-2016) de un espacio museológico dedicado a la vivienda popular y obrera en Barcelona. El proyecto del MUHBA es un proyecto coproducido entre la Ciudad (Distrito y el Plan de Barrios de Barcelona i MUHBA) y la Asociación de Vecinos y vecinas. Dispondrá de tres espacios en los que se podrá visualizar cómo era el interior de las casas baratas en tres momentos históricos: 1929, momento de la construcción del polígono; años 1960 y "actualidad", es decir cómo eran estas viviendas en el momento del inicio de la remodelación del barrio. Aparte de un espacio expositivo y una sala de conferencias.

La nueva instalación también presenta aspectos de cogestión ya que algunos de sus espacios 


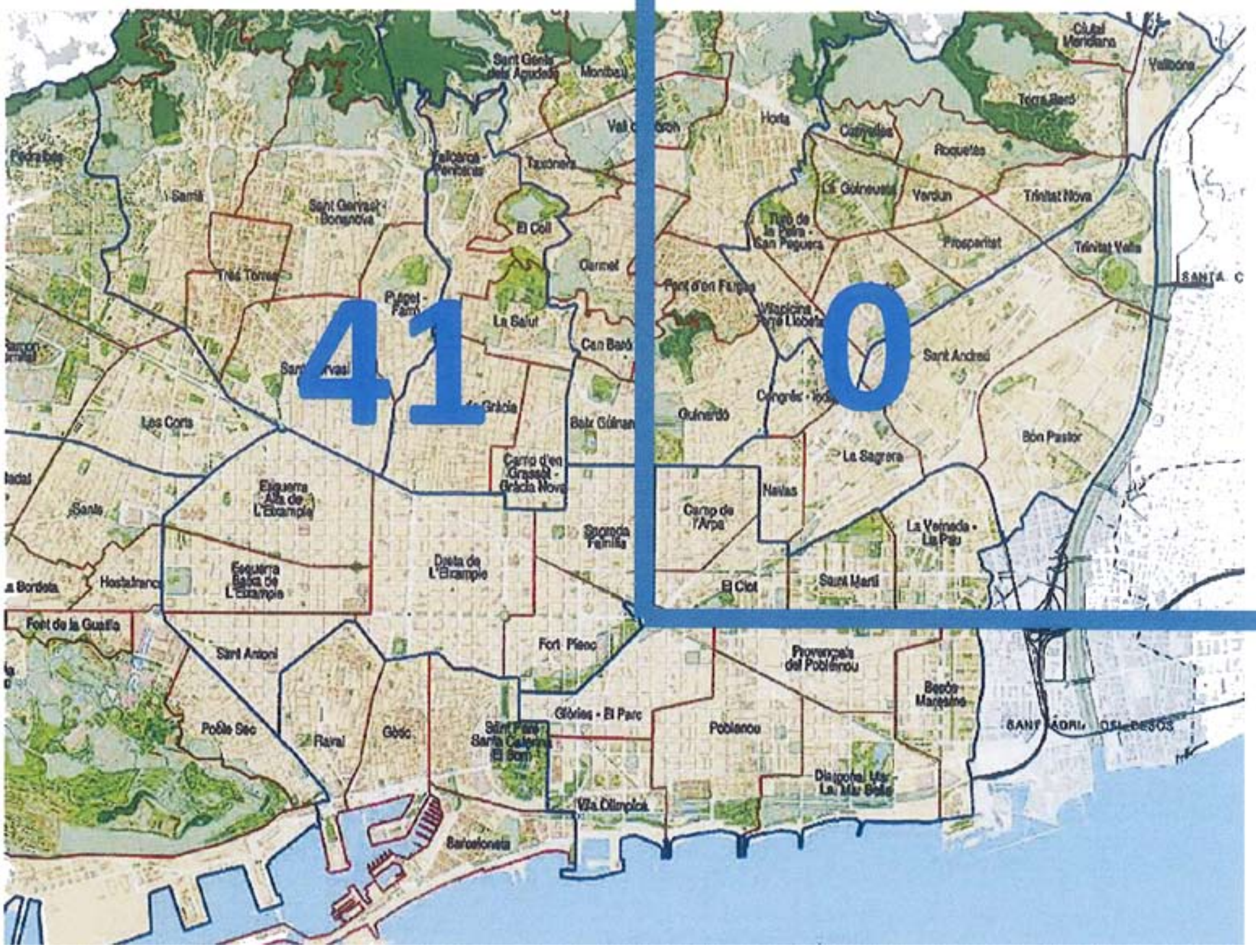

En Barcelona existe un "cuadrante 0 museístico" que abarca la totalidad de los distritos de Nou Barris y Sant Andreu donde se ubica el barrio del Bon Pastor. Fuente: Presentación del MUHBA sobre los nuevos espacios propuestos para estos distritos (2016)

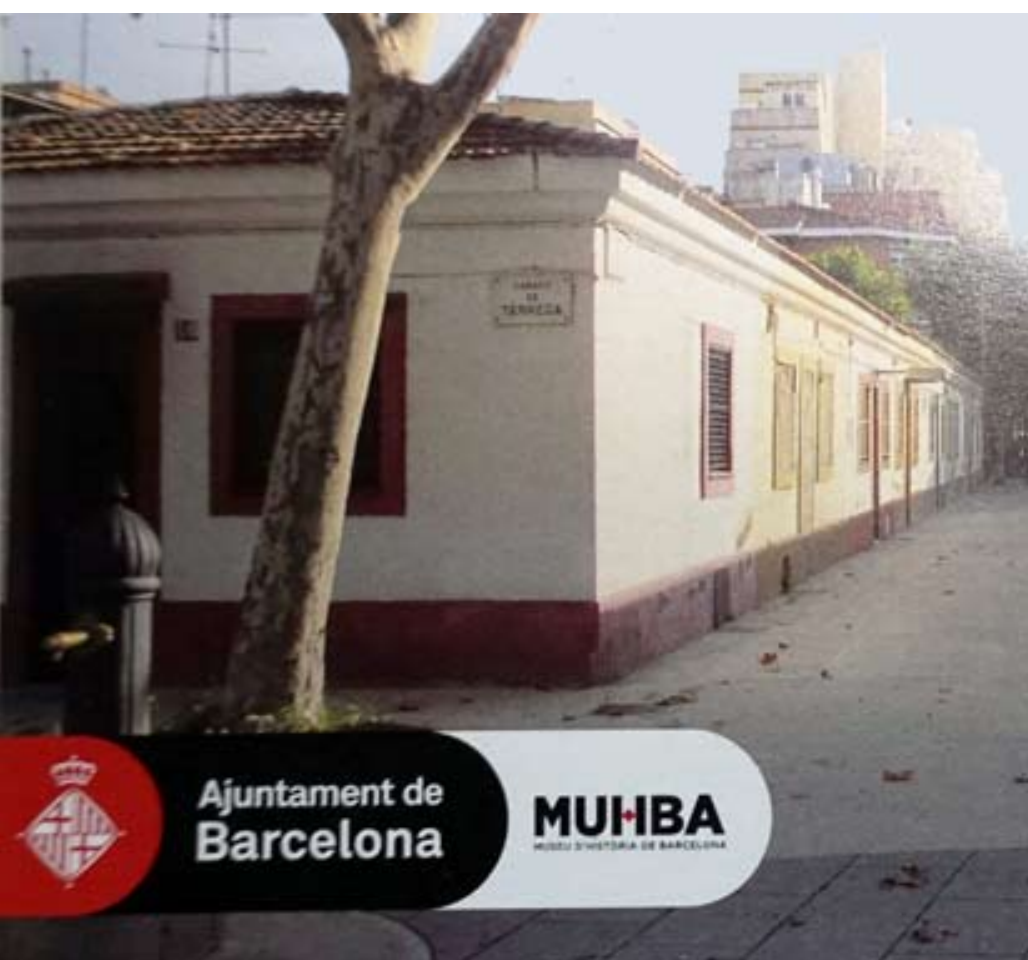

\section{BON PASTOR, LABORATORI D'UN BARRI}

JORNADA

30.03.2019

MUHBA BON PASTOR

Folleto editado por el MUHBA para una presentación del proyecto museográfico de las casas baratas. Las casas baratas que aparecen en la foto son las dos hileras de casas que se presenrvan en el proceso de remodelación. Fuente: Muhba 2019 
Estos factores son los que explican la convergencia entre los dos proyectos "Hagamos la memoria" y "espacio museístico". Ambos proyectos corren en paralelo, pero con muchas intersecciones entre ellos. Por ejemplo, el espacio del museo se abre a la plaza "Vilabesos", recientemente remodelada y nombrada. Para este espacio público, los talleres participativos sugirieron levantar un monumento a las víctimas de los bombardeos fascistas de 1937, una "exclamación" en terminología de Sennett. Así, las ideas para el diseño preliminar de este monumento están condicionadas, en su ubicación, escala e incluso en materiales, por la existencia del espacio del museo.

Se abre pues un espacio intermedio entre el "a priori" y el "a posteriori". En una situación en la que el problema de la accesibilidad física a la vivienda, el espacio público o el transporte público está relativamente bien resuelto; cuando las demandas sobre los servicios urbanos (salud, vivienda, educación) se cumplen en el marco actual de escaso Estado de Bienestar, los vecinos de un territorio comienzan a preocuparse, también, por otras dimensiones de accesibilidad. Dimensiones de carácter eminentemente simbólico sobre su derecho a comprender y expresar "de dónde vienen y hacia dónde van", capturar y escribir su memoria, organizar, gestionar y difundir los documentos sobre los que se cimenta este viaje hacia la memoria cívica. También reclama acceso al diseño del espacio donde se despliega su vida diaria, un acceso como "actores-agentes" a la producción efectiva del espacio urbano y una clara oposición a ser considerados meros "usuarios" del espacio y de los bienes y servicios de la ciudad funcional.

El co-diseño y la co-producción significa articular nuevas formas de participación ciudadana, articulaciones innovadoras que superen el peldaño de la mera consulta, para acceder así a las dimensiones de la "creación" de espacios públicos y de caminos organizativos que permitan un nivel satisfactorio de autogestión de la dimensión simbólica de la ciudadanía y del entorno. Se necesita una nueva actitud por parte de la administración local, entendiendo que esta "accesibilidad a lo simbólico" es parte del conjunto de acciones contra la exclusión social.

Por último, solo quedaría apuntar que el proyecto en Bon Pastor está todavía en proceso (las elecciones municipales de 2019 y la crisis de la pandemia COVID19) han ralentizado su despliegue. Sin embargo se puede afirmar que marca un itinerario socialmente innovador destinado a permitir a los ciudadanos ejercer de manera efectiva el derecho a la ciudad. Participación y co-diseño (ojalá sea co-produccion) se presentan aqui como una manera de crear un espacio de diálogo entre el "simbolismo a priori" y el "a posteriori" permitiendo un acceso a la gestión de lo simbólico en procesos "bottom-up". 


\section{BIBLIOGRAFIA}

AA.VV. 2020. «A Letter on Justice and Open Debate». Harper's Magazine, 7 de julio de 2020. https://harpers.org/a-letter-on-justiceand-open-debate/.

ANGOSTO, Salvador. 2019. «Mapping the History of a Territory: Bon Pastor (Barcelona) - Social Remembrance and Heritage Project». Acta Universitatis Lodziensis. Folia Philsophica-Ethica-Aesthetica-Practica, n. ${ }^{\circ} 33$ : 37-55. https://doi.org/10.18778/0208$\underline{6107.33 .03}$

ASCHER, François. 2004. Los nuevos principios del Urbanismo. El fin de las Ciudades no está a la orden del día. Madrid: Alianza Editorial S.A.

BHAT, Chandra, HANDY, Susan; KOCKELMAN, Kara; MAHMASSANI, Hani, CHEN Qinglin, y WESTON Lisa. 2000. «Developmento of an Urban Accesibility Index. Literature Review». Austin.

BOVAIRD, T- LÖFFER, E (ed). 2016. Public Management and Governance. Third edition. London: Routledge.

BRANDÃO, Pedro. 2011. La imagen de la Ciudad: Estrategias de identidad y comunicación. Barcelona: Edicions de la Universitat de Barcelona.

BUSQUET, Grégory. 2019. «Right to the City». En The Wiley Blackwell Encyclopedia of Urban and Regional Studies.

CAPEL, Horacio. 2003. «A modo de introducción: Los problemas de las ciudades. Urbs, Civitas y Polis». En in Capel, Horacio (Coord) Ciudades, arquitectura y espacio urbano, 9-24. Alicante: Cajamar.

CIAM. 1933. La Charte d'Athènes. 1957. a ed. Paris: Éditions de Minuit.

AA.VV. BON PASTOR y CR POLIS. 2015. «Fem la Memòria del Bon Pastor». Wordpress. Fem la memòria del Bon Pastor (blog). 2020 de 2015. https://ja.cat/OHmDv .

DICTRICTE DE SANT ANDREU. 2009. «Projecte d'intervenció integral del Bon Pastor- Baró de Viver». Ajuntament de Barcelona.

EVANS, Graeme. 2009. «Accessibility \& Urban Design-Knowledge Matters». semanticscholar.org

FERNANDO, Alonso. 2007. «Algo más que suprimir barreras: conceptos y argumentos para una accesibilidad universal». TRANS: revista de traductología 2: 15-30.

HARVEY, David. 2013. Ciudades rebeldes. Del derecho a la ciudad a la revolución urbana. Potential Analysis. Vol. 31. Tres Cantos: Akal. https://doi.org/10.1007/s11118-009-9129-5.

IDHC. 2009. «declaració universal de drets humans emergents | declaración universal de derechos humanos emergentes I universal declaration of emerging human rights | declaration universelle des droits de'l homme émergents». Institut dels Drets Humans de Catalunya. http://www.idhc.org .

IWARSSON, Sussane, y STÅHL Agneta. 2003. «Accessibility, usability and universal design- Positioning and definition of concepts describing person-environment relationships». Disability and Rehabilitation 25 (2): 57-66. https://doi.org/10.1080/ dre.25.2.57.66.

LEFEBVRE, Henri. 1971. La revolución urbana. 1973. a ed. Madrid: Alianza Editorial.

LEFEBVRE, Henri. 1974. La production de l'espace. 4ª 2000. Paris: Anthropos.

LEFEBVRE, Henri. 1978. El derecho a la Ciudad. 4. Barcelona: Ediciones Península.

LYNCH, Kevin. 1960. The Image of the City. Cambridge, Mass.: The Technolgy Press \& Harvard University Press.

LYNCH, Kevin. 1985. La buena forma de la Ciudad (1981). Barcelona: Gustavo Gili.

LYNCH, Kevin. 2008. La imagen de La ciudad. Barcelona: Editorial Gustavo Gili, S.L.

MICHONNEAU, Stéphane. 2001. Barcelona: memòria e Identitat. Monuments, commemoracions i mites. Barcelona: Euno Editorial.

MUÑOZ, Francesc. 2008. Urbanalización. Paisajes comunes, lugares globales. GG Mixta. Barcelona: Gustavo Gili.

NORA, Pierre. 1989. «Between Memory and History: Les Lieux de Mémoire». Representations Special Issue: Memory and CounterMemory (26): 7-24. http://www.jstor.org/stable/2928520. 
PADILLA, Samuel. (2015). Producción de Espacio Público [X] Participación Ciudadana. El proyecto de espacio público resultado de procesos de participación ciudadana [Barcelona]. http://tdx.cat/handle/10803/309288

PIRIE, G H. 1979. «Measuring accessibility: a review and proposal». Environment and Planning A. Vol. 11.

POL, Enric. 1997. «Symbolism a priori • Symbolism a posteriori». En Remesar, A (Ed) Urban Regeneration. A Challange for Public Art, 140. Monografies Psico- Socio- Ambientals 6. Barcelona: Edicions de la Universitat de Barcelona.

RAPOPORT, Amos. 1982. The Meaning of the Built Environment. Tucson: The University of Arizona Press.

REMESAR, Antoni. 2016. "New Urban Decorum? Aesthetics To and Fro». En In Gralińska-Toborek;A -Kazimierska-Jerzyk, W (ED) Aesthetic Energy of the City, 19-54. Lodz: Wydawnictwo Uniwersytetu Łódzkiego (Łódź University Press). https:// wydawnictwo.uni.lodz.pl/produkt/aesthetic-energy-of-the-city/.

REMESAR, Antoni. (2020). Co-design of public spaces with local communities. In Tony Bovaird and Elke Loeffler (ed) The Palgrave Handbook of Co-Production of Public Services and Outcomes (in print). Palgrave Macmillan. http://doi.org/10.1007/978-3-03053705-0

SALAS, Xavier. 2015. «L'artista com a facilitador en els processos de participació ciutadana: el cas Baró de Viver a Barcelona». Tesis Doctoral, Barcelona: Universitat de Barcelona. http://hdl.handle.net/10803/308505.

SALAS, XAVIER. 2016. «Bon Pastor (Barcelona) Un territorio en construcción».On the w@terfront [en línia], 2016. http://raco.cat/ index.php/Waterfront/article/view/308596/398605.

SALINGAROS, Nikos A. 2010. P2P Urbanism. Solingen: Umbau--Verlag.

SANZ, Alfonso. 1997. «Movilidad y accesibilidad: un escollo para la sostenibilidad urbana.»Construcción de la Ciudad Sostenible, Documentos.

SENNETT, Richard. 2018. Building and Dwelling. Ethics for the city. New York: Farrar, Strauss and Giroux.

SOJA, Edward W. 1996. Thirdspace. Journeys to Los Angeles and Other Real and Imagined Places. Oxford: Blackwell Publishers Ltd.

SOJA, Edward W. 2008. Posmetrópolis. Estudio crítico sobre las ciudades y regiones. Madrid: Traficante de Sueños.

TAKANO, Guillermo; TOKESHI, Juan. 2007. Espacio Público en la ciudad popular: Reflexiones y experiencias desde el Sur. Lima: desco Centro de Estudios y Promoción del Desarollo.

VALERA, Sergi. 1993. «Estudio de la identidad social y los aspectos simbólicos del espacio urbano desde la Psicología Ambiental .» Universidad de Barcelona.

VALERA, Sergi, y POL Enric. 1994. «El concepto de identidad social urbana: una aproximación entre la psicología social y la psicología ambiental». Anuario de psicología 62: 27.

VATTIMO, Gianni. 1986. «Ornamento y Monumento». En El fin de la Modernidad. Nihilismo y Hermenéutica en la cultura posmoderna, 159. Barcelona: GEDISA.

VERGEL, Javier. 2017. Ciudad, comunicación, identidad y participación: hacia un sistema de información para el Barrio del Bon Pastor, Barcelona: Universitat de Barcelona. http://hdl.handle.net/2445/117925.

WEGGE, Klaus Peter, y ZIMMERMANN Dirk. 2007. «Accessibility, Usability, Safety, Ergonomics: Concepts, Models, and Differences». LNCS. Vol. 4554.

\section{Reconocimientos}

Este trabajo forma parte de la investigación en curso "Espacio público, participación creativa, memoria cívica" proyecto HAR2017-88672-R, Ministerio de Economia y Competitividad (España) 